\title{
THE REGULATORY PROCESS: A FRAMEWORK FOR ANALYSIS
}

\author{
Marver H. Bernstein*
}

The literature of administrative regulation in the United States, as it has developed over a period of several decades, yields an inadequate and distorted conception of the regulatory process. Most lawyers have tended to consider governmental regulation of economic enterprise within the framework of legal theory, while administrators and students of administration have tended to analyze regulatory activity in terms of the conventional categories of governmental administration. These divergent attitudes toward government regulation are based on different sets of values, assumptions, objectives, and professional training. Areas of agreement have not been staked out; significant differences in the consequences of the approaches have not been identified. Applications of each approach have been charged with value judgments whose premises have rarely been examined and tested. One result has been the tendency, on both sides, to show more interest in what ought to be taking place in regulatory administration than in what goes on.

Although the literature of the regulatory process has concentrated on technical and procedural issues presented in the professional jargons of the lawyer and the administrative expert, the modern debate over the reform of administrative regulation has been part of and a major expression of the contemporary debate on the role of government in industrial society. Since the creation in 1933 of a special committee on administrative law by the American Bar Association, battle lines have been drawn between bureaucrats and defenders of liberty, between fighters for social change and protectors of privilege, between administrative absolutists and believers in a government of laws and not of men. At stake in these legislative struggles over "administrative procedure" have been such fundamental issues as the proper scope of the government's role in economic life, the appropriate limits to the growth in administrative discretion, and the conditions under which increasing governmental activity affecting economic life would be tolerated or accepted.

The primary characteristics of the literature of administrative regulation need only be summarized here. Research and discussion have focused heavily upon adjudicatory procedures and the administrative structure of the independent regulatory commission. The regulatory programs of departments and agencies other than independent commissions have received scant attention from reformers or scholars. Similarly, most studies have concentrated upon adversary proceedings,

* A.B., A.M. 1940, University of Wisconsin; Ph.D. in Politics 1948, Princeton University. Professor of Politics, Princeton University. Member, Organizing Committee, President's Conference on' Administrative Procedure, I960; Associate Staff Director, Special Committee on Federal Conflict-of-Interest Laws, Association of the Bar of the City of New York, 1958-60. Author, Reguzating Business BY IndePENDENT Commission (1955), The Job of the Federar. Executrve (1958). Contributor to professional periodicals. 
both within the agencies and the courts. This emphasis has diverted attention from such important processes of administrative regulation as negotiated orders, investigations, selection of cases to institute, administrative determinations, enforcement and compliance activities, and other activities that do not involve overt adversary proceedings. As a consequence, differences between "regulatory" and other types of administrative activities of government have probably been exaggerated.

The addiction to the adversary process and the deference accorded private rights and privileges have not been matched by any comparable attention to substantive issues of public policy. The effects of regulatory policy and operations on the regulated interest and on consumers have rarely been studied. Very limited use has been made of economic analysis in reviewing and appraising regulatory policy or in determining what conditions regulatory agencies should investigate, whether violations of law have taken place, and what to write into orders. The lack of empirical work has extended even into areas of major concern to lawyers, such as the functions and role of hearing examiners and relations between agency heads and hearing examiners.

As current discussions of "delay" as the number-one problem of the regulatory commissions indicate, the literature exhibits predilection for treating symptoms rather than basic causes of ineffectiveness in regulation. Chronic reform proposals, such as those relating to administrative courts, seem to emerge not from fresh analyses of problems and issues, but from a priori premises about advantages claimed for courts and judges over agencies and their heads in the dispensation of justice. The assumption of expertise, supposedly an inherent advantage of regulation by commission, has not been tested empirically, although a running tide of harsh criticism of the staffs and heads of regulatory commissions has become commonplace in political life.

Policy-making processes in regulatory agencies have scarcely been studied, and the forces influencing policy-making have not been identified in specific regulatory programs. Little concern for the political context of regulation has been demonstrated. The temptation to rely heavily on form-the structure of an organization, uniform procedures of adjudication, the constitutional role of the Presidenthas been powerful. The inability to come to terms with the political character of regulation has been glorified as an honorable escape from politics, and it has sanctified the drive toward further judicialization of administrative regulation. Finally, in the reformist orientation, distinctions between ongoing regulatory activities and prescriptions for improvement have been obscured, perhaps largely because felt needs to supply formulas for reform have outrun the available empirical data on the political and technical setting of a particular regulatory program.

\section{Categories of Analysis}

One condition underlies the diagnostic and prescriptive aspects of the literature of the regulatory process. This condition is a failure in analysis that has warped our 
conception of the regulatory process, encouraged us to rely excessively on minor and somewhat dubious technical reform measures to achieve or obstruct major changes in regulatory policy, and enabled us to avoid discussion of policy considerations. The failure in analysis seems to stem principally from a reliance on untested classifications and dichotomies that bear little or no relation to regulatory operations.

\section{A. Separation of Powers}

The most prominent categories in the literature of regulation have been legal in origin and application. The tripartite division of powers-legislative, executive, and judicial-has been of great import. However, the work of the regulatory agencies-departments and commissions-has not fitted conveniently into these categories of separation of powers. Many modern institutions were developed because many types of regulations established and enforced by the three traditional branches of government were not effective. The origin of many commissions was based partly on the premise that the separate functions had to be closely coordinated by men of experience and expertise. Yet, much of the analysis of the work of the agencies has been premised on the desire to insulate the three powers from each other in keeping with historic tradition. Given this premise, there has not been a satisfactory synthesis of the desires for more effective regulation, for promoting impartial equity for the individual, and for avoiding overconcentration of power in the hands of individuals. Categories drawn from theory and practice of separation of powers have been utilized not as tools to analyze regulatory operations, but as verbal support for continuing judicialization of the regulatory process.

\section{B. Rule-Making vs. Adjudication}

Another important set of categories, the dichotomy of rule-making and adjudication, has been an offshoot of the basic structure of three separate powers. These categories have not furnished a constructive basis for the examination of the workings of the regulatory process. Rule-making has been identified with policy formulation, while adjudication has been defined as the process of deciding individual cases. Some observers and practitioners find a conflict between policy-making and adjudication that arises from profound differences in attitude and procedure. Labeled a legislative function, policy-making, it is said, is formulated normally on the basis of extensive and informal interchanges between regulatory agencies and interested parties and delegation of work from agency heads to staffs. Judicial hearings, so the analysis runs, are not appropriate ingredients of rule-making or policy-making.

In sharp contrast, however, adjudication has been conceived as a process that depends on formalized procedures, the creation of a record with adequate opportunity for presentation and cross-examination of evidence, and final judgment on the basis of the record alone by the persons responsible for decision. ${ }^{1}$

\footnotetext{
${ }^{1}$ See, e.g., Hector, Problems of the CAB and the Independent Regulatory Commissions, 69 YALE L.J. 931 (1960) [this report has been published as a committee print by the Senate Committee on Government Organization, 86th Cong., 2d Sess. (I960)].
} 
The distinction between the legislative-executive function of formulating policy and the judicial function of deciding individual cases lies at the root of reform proposals that would surgically cut off the adjudicative function from the policy function. The basic notion has appealed, from time to time, not only to those who hope to diminish administrative discretion and coercive power in the hands of administrators, but also to those who would make more effective use of regulatory agencies for policy purposes that may enlarge the scope of governmental power. Despite a good deal of initial enthusiasm in support of these proposals, their staying power has been rather weak. The withering away of support for these schemes of dismemberment may be accounted for in part by the uncertainties surrounding the probable attitudes of judges of administrative courts toward agency policies. Perhaps judges might, over time, become quite sympathetic to the policy problems of the agencies with whom they deal on a continuing basis.

Sympathy for such objectives as eliminating delays in reaching decisions, promoting fairness and objectivity in the adjudicative process, and tooling up the agencies to administer their affairs more vigorously should not lead to uncritical acceptance of the dichotomy between rule-making and adjudication. The major difficulty is simply stated: the categories of rule-making and adjudication, which can be applied in a limited way to distinguish the end products of administrative regulation-namely, rules and orders-often cannot be meaningfully applied to the operating processes by which rules and orders are produced. Two major factors account for the intermixture of broad policy-formulation and decision-making in individual cases. The first is the manifest difficulty in many instances of formulating a guiding policy in advance of the consideration of individual cases because the issues involved are highly complex and controversial, or involve matters that remain substantially unresolved by existing legislation. The second factor is that many policies cannot be determined or ought not to be decided except in connection with the processing of specific cases of adjudication.

The distinction between rule-making (policy-making) and adjudication can rarely be translated into regulatory operations as long as critical interests are at stake in a case under adjudication. Each case may confront such a clash of interests that only a vague policy, or none at all, emerges from the individual case decision. When policies are broad and vague, they generally prove to be unsatisfactory guides to decision in adjudicated cases. And when policies are too tight and specific, they may be applicable only to relatively few cases. What is needed is an appropriate balance between the two extremes in order to utilize rules as effective policy guides to adjudicators and to make adjudicatory decisions more productive of usable policy guides. While the temptation to avoid policy-formulation is endemic in regulatory agencies, it must also be recognized that the obstacles to policy-planning and formulation are powerful in many regulatory settings. Indeed, the most insistent line of criticism directed at regulatory agencies that handle large volumes of adjudicated cases is their marked incapacity to plan their operations and formulate 
guiding policy. But it is neither certain nor probable that policy functions would be carried on more effectively by regulatory agencies deprived of jurisdiction over adjudication.

\section{Regulation vs. Promotion}

A popular classification in the literature of administrative regulation attempts to distinguish between programs that regulate and those that promote business enterprise. Regulation, it is claimed, differs distinctively from promotion in several respects. It is argued that regulation is administered optimally by independent multiheaded commissions rather than by departments or other types of agencies; it is carried out by specialized operations of rule-making and adjudication that are distinctively different from so-called executive-type and other administrative operations; and its integrity can be maintained only by separating it sharply from programs that promote private business activity. It is also widely held that regulatory programs require for effective administration more continuity of direction and more permanence and consistency in policy-development than do other types of government programs. Associated closely with these desiderata is the belief that regulation requires a quality of professionalism and expertness of judgment that is higher than that of nonregulatory operations and is safeguarded against the viscissitudes of politics and the varying tempers of changing presidential administrations. This attitude is reflected, for example, in the opinion of the Board of Investigation and Research in 1944 on transport regulation:2

To place rate regulation in the hands of an executive officer would be to move ... toward politics rather than away, to diminish that protection from partisanship which is desirable.

Regulation, moreover, has generally been conceived to be a narrow, self-contained process more or less separable from the main drift of national economic policies. This insular conception of regulation has been paid continuing lip service despite increasing recognition that some regulatory policies should be closely integrated with other governmental programs in order to maximize their effectiveness. As a conceptual tool of analysis, the dichotomy of regulation and promotion provides a built-in bias that supports a narrow, mechanistic view of the regulatory process, focuses attention on judicial functions of regulatory agencies, and unduly discounts the need for political leadership to protect the integrity of a regulatory program.

From an analytical point of view, three criticisms should be noted. First of all, there is remarkably little empirical evidence in the public documents and the research literature in support of the dichotomy of regulation and promotion, and some evidence opposing it. Second, there is some evidence suggesting that the separability of regulation from promotion varies according to the nature of the regulatory program. For example, where the dominant or exclusive purpose of public regulation of business is protection of public health and safety, as in the case of the Atomic

* Board of Investigation and Research, Practices and Procedures of Governmental Control, H.R. Doc. No. 678,78 th Cong., $2 \mathrm{~d}$ Sess. I4I (I944). 
Energy Commission and the National Institutes of Health, a close identity of interest tends to develop between the agency's conception of the public interest and the individual firm's business interest. No firm wants to construct an unsafe nuclear reactor or market an unsafe vaccine. Moreover, when the state of technology in a regulated enterprise is unstable, rapidly changing, and relatively untested, the dividing line between regulation and promotion may be obscured, if not eliminated.

Lastly, regulation of practices in one industry may seriously affect the conduct of others as well. Subsidies available to one form of transportation may adversely affect those media not eligible for public assistance. What is regulatory with respect to one industry may be promotional in its impact on another. And regulations enforced by one agency may effectively nullify the promotional efforts of another agency. ${ }^{3}$

\section{Commissions vs. Noncommissions}

As noted already, a major distinction has been made in the literature between commissions and other types of administrative structures, together with the insistent view that the commission is the ideal-type structure for regulatory programs. The contrasts commonly drawn between commissions and other agencies have not been documented in depth. Diversity among regulatory programs in commissions has been glossed over. Empirical data is lacking to support widely held contentions that the relationship of commissions to congressional committees is characteristically different from that of other agencies to congressional committees. While multiple direction of commissions has been expounded as a better guarantor of fairness, sound judgment, and continuity of policy than single-headed direction is said to be, commissions appear to have encountered more and sharper criticism of regulatory policy and procedure from all sources than have the executive departments as a group.

One important difference between commissions and other agencies suggested by recent political experience is the finding that modern presidents have tended to accord appointments to commissions a relatively low priority. They have given little consideration to the appointment of men who might increase the internal strength of commissions. ${ }^{4}$ If the quality of commissioner appointments has tended

${ }^{8}$ A former member of the Federal Maritime Commission commented: "Today the Government regulates transportation by promoting transportation, and by promoting it, the Government actively regulates it. The time has come to cease treating regulation and promotion as though they were separate and distinct. I not only believe that they overlap, but that in fact it is impossible to tell where one begins and the other ends. Transportation facts and realities have wiped out the dividing line. We can continue, for convenience's sake, the loose use of the term regulation when we primarily think of restricting the activities of carriers, although restricting one carrier, or group of carriers, protects and promotes others; or when we think of rate regulation, although more often than not approval of low rates is intended to promote his competitive status. We may think of promotion as doing something for a carrier, such as payment of subsidies; yet keeping competition from him by regulation may promote a carrier as much, or more, than a subsidy, while denying a carrier promotion through a subsidy may mean restricting him as effectively as through regulation." From memorandum of Raymond S. McKeough, p. 5-6, commenting on Secretary of CoMmerce, A Report to the PREsident: Issues Involved in a Unified and Coordinated Federal Program for Transportation (1950).

"As James M. Landis stated: ". . . I have stressed the lack of concern in the last decade in the office of the President with manning these agencies with personnel of high competence and great 
to run below that of other agency heads, the difference runs directly contrary to a major expectation supporting the theory of the independent commission.

E. Conceptual Inadequacy of the Categories

The categories under review here have been the principal conceptual tools available for analysis of the regulatory process. They have not made affirmative contributions to the analysis of what happens in regulatory operations. Their major use has been to provide a basis of objection to what takes place because it does not fit the categories. They have limited the analysis of the multifarious means for developing policy. They have not been applicable to the extensive use of administrative techniques of negotiation, discussion, and consent that have developed in almost all regulatory programs in response to the practical needs of the times. They have failed to study and account for many administrative and ministerial operations by regulatory agencies that have been followed on a practical basis with widespread acceptance. Almost no attention has been given to alternatives to formal hearings as devices for the participation of interested parties. Methods of regulation other than formal adjudication remain largely the private knowledge of direct participants in the regulatory process.

Similarly, these classifications have focused not only on policy considerations and goals of public policy, but rather upon mechanistic concerns. Regulatory activities are appraised customarily not in terms of their impact on regulated interests or their contribution to policy goals, but rather in terms of such factors as average processing time for cases of adjudication, whether commissioners write their own opinions, or the degree of separation between examiner and his employing agency. In their preoccupation with procedure and organization, these categories of analysis have helped to divert attention from the underlying issues and checked the progressive development of public policies.

II

The Need for Empirical Work

Whatever utilities the dominant slogans and theologies of administrative regulation may have had for resisting policy change or for proposing limited organization changes, they have contributed neither a realistic understanding of the nature of the regulatory process nor a fresh approach to the major problems of regulatory policy in particular fields. One conclusion emerges from a review of the characteristics of the literature and the dominant categories of analysis of the regulatory process: there is a critical need to overcome the conspicuous shortage of empirical studies of regulatory operations, policy issues, and regulatory results. Without the knowledge and stimulation that empirical research might provide, we are likely to remain on dead center in our understanding of the regulatory process and in our prescriptions for reform.

quality. ..." From interview with James M. Landis, What's Right and What's Wrong With Government Regulation, U.S. News and World Report, March 27, 1961, p. 83. 
The need for empirical work lies in three intimately related areas. Perhaps the task of highest priority is the critical need for conceptual tools of analysis to evolve a more comprehensive concept of the regulatory process with an orientation toward policy and processes of policy-formulation. Only through imaginative empirical work are we likely to acquire the raw material for developing such tools. A second task is the formulation of appropriate levels of generalization that will enable scholars and practitioners to comprehend the rich diversity of regulatory operations and experience in the federal government and elsewhere. It requires the formulation of generalizing hypotheses that are subjected to empirical testing. Empirical work is also needed to identify the most productive methodologies for carrying on research into operations and for evaluating policy developments.

\section{A. Categories of Analysis}

The starting point in the development of an improved conception of the regulatory process is the formulation of categories of analysis that grow out of operations of regulatory agencies. The task must be premised on the appreciation of the enormous diversity among regulatory agencies and programs. It may be possible, for example, to develop a classification of regulatory programs in terms of functional goals that would, in the first instance, recognize known differences in existing programs. Several types of regulatory programs might be differentiated in this way: I. Public utility programs that embrace relatively comprehensive controls over an industry in which competitive forces are inapplicable or tend to produce destructive or otherwise adverse consequences

Such programs may, potentially or actually, bite deeply into the management of individual firms in exercising some measure of control over rates, the quantity and quality of service, consumer relationships, safe performance, financial structure, and engineering soundness. They may also exercise strategic control over entry into and abandonment of a business. Such programs present the highest degree of governmental involvement in privately managed enterprises and theoretically maximize opportunities for controversy between regulators and regulated firms. 2. Safety-oriented programs in which the protection of public safety is the sole or overriding goal of public policy

While such programs may lead to intensive governmental involvement in an industry or individual firm, as in the case today of the regulation of nuclear reactors by the Atomic Energy Commission, they may often take advantage of a clearer and more widely accepted policy goal and a close measure of agreement between regulators and regulated on the nature of the public interest.

3. Financial programs that focus on the goal of protecting the integrity of the fiduciary relationship between financial institutions and the public

The traditional activities of the Comptroller of the Currency, the Federal Deposit Insurance Corporation, the Federal Reserve System, and the Home Loan Bank Board are examples. There tends to be a high degree of acceptance of regulation by 
the regulated institutions, perhaps in part because of the promotional value to those institutions of receiving a federal stamp of approval of their probity and managerial soundness.

4. Programs incidental to the ministerial operations of the government and the management of public property

These programs may, in their limited areas of operation, vest in the government a high level of discretionary power comparable to that possessed by managers of private business. They may, however, provide a strategic control that goes beyond the control of internal governmental housekeeping. For example, in its control of the use and disposition of the public domain, as in the minerals-leasing program of the Department of the Interior, the Government may exercise, actually or potentially, considerable control over those authorized under stated conditions to use or exploit public property.

5. Rather specialized industry-oriented programs, undertaken often at the behest of private parties to stabilize the industry or some of its aspects

For example, under the Perishable Agricultural Commodities Act, ${ }^{\bar{j}}$ the Department of Agriculture adjusts and umpires disputes between shippers and receivers of fruits and vegetables. In this program, because of the danger of rapid deterioration of the produce, a process of quick adjustment made more or less on the spot seems to offer the greatest measure of protection for both shippers and receivers. Here, the government regulators may be offering essentially a service that the industry itself is unable to supply or can supply only under less convenient or less advantageous circumstances. In such programs, limited goals of public policy may be widely or even enthusiastically embraced by the limited private interests involved, and the process of regulation may feature operating methods far removed from formal processes of rule-making and adjudication.

6. Programs designed to maintain a balance, loosely defined in statutes and administrative orders, between economic groups, such as relations between labor and management, or between securities dealers and investors

Acceptability of policy goals may range from broad consent to bitter controversy and, within any single area of regulation, is likely to vary over time.

7. Programs designed to stimulate or enforce competitive conditions in the marketplace, such as the antitrust program of the Department of Justice and the antimonopoly activities of the Federal Trade Commission

It may be useful to make a distinction between regulatory programs that establish certain minimal conditions affecting the level of competition and those that strive to eliminate restraints of trade or monopolizing activities. An example of the former might be the labeling programs and prohibitions against false and misleading advertising in the FTC, in contrast to the FTC's activities to prevent mergers that tend to restrain trade or tend toward monopoly.

No claim is made that the suggested classification of regulatory programs, roughly

${ }^{5} 46$ Stat. 53 I (1930), 7 U.S.C. $\$ \$ 499 a-499 r$ (1958). 
according to policy goals, accommodates all existing regulatory programs or identifies the most significant differentiating characteristics of the range of such programs. Certainly, other types of classifications need to be formulated and tested. For example, for some purposes, it may be helpful to classify these programs according to their degree of promotional content, or their utilization of incentives to develop consent and stimulate compliance, or their relative insularity as opposed to their relationship to other governmental programs and public policies. For some purposes, such variable factors as the state of technology in a regulated industry or the character of the regulated industry (numbers of firms, degree of concentration of output and financial control, significance of competitive forces, etc.) may be useful tools of analysis.

To put the matter in its broadest and most challenging scope, we need a typology of regulatory situations that encompasses the variables relevant to the policy goals and operations of regulatory programs. It should probably include such factors as organization structure; political sensitivity of policy issues; the relative importance and use of adjudication and formal rule-making processes; the utilization of negotiating devices and other conventional administrative methods; degrees of discretion exercised by various levels and types of agency personnel; the relative autonomy or interdependence of regulatory programs; the nature and role of interest groups; the structure and character of regulated firms and industries; the significance of political leadership in maintaining progressive revision of goals and policies and in molding the character of regulatory programs; the nature of congressional involvement and concern; the role of catastrophe and crisis in stimulating and crystalizing demands for policy revision; and the impact of international considerations on the formulation of policy.

\section{B. Levels of Generalization}

Closely related to the task of formulating categories of analysis is the development of meaningful generalizations. Without such categories, the potential for generalization is very meager. But generalizations are not magically conjured up from the categories. The possibility of developing usable categories and generalizations by a series of successive approximations is suggested.

It should be possible to develop some analytical categories that seem to fit the operating characteristics and processes of a particular regulatory program. For example, through empirical analysis, the researcher can discover whether a particular program is a public-utility-type program or whether it can be classified more appropriately some other way. It should be feasible to develop sets of categories for programs of the same general functional type.

A second step might call for a closer analysis of the categories developed for each of several functionally similar programs-for example, two or three programs of financial regulation, or a group of public-utility-type programs. In this way, it is likely that one set of categories might be formulated to apply across the board to all programs of a particular functional type. 
A third step may be a combination of various types of programs into a single classification for which a single set of categories may be developed out of the empirical data of operations. Obviously the combination of functional types of programs would necessarily be not quite as close as the combination of programs indicated in the second step.

Once satisfactory categories of analysis are established, it may be possible to examine various combinations of variable factors that seem to produce an observable regulatory result. In this way, relationships among variable factors may be suggested that may, in the long run, make it possible to offer some predictive suggestions about the operating characteristics and effective performance of a given program. It is likely that only through such successive steps may levels of generalization be developed that will have substantial interpretative and predictive value.

\section{Policy-Formulation and the Probing of Policy Issues}

Hand in hand with the effort to develop an analytical synthesis of the regulatory process must proceed the probing of policy issues. For this purpose, an emphasis on a regulatory program rather than its administrative instrument appears to be practicable. Again, two related efforts seem to be required that do not exclude due process or managerial considerations and draw substantially on a study of the economic background and effects of policies. The first emphasizes the process of policy-development, the heart of administrative regulation. The second is the evaluation of policies and the prescription of alternatives.

In explorations of policy-formulation, a number of emphases or approaches may be suggested. Analyses are needed of the characteristics of the several aspects of policy-formulation: legislation, rule-making, adjudication, selection of cases, negotiation, investigation, administrative determination, inquiries for planning purposes, enforcement and compliance activities, appraisal of performance and regulatory effects, defending the jurisdiction and vested interests of the program, public information activities, and so forth.

In addition, a better understanding is needed of the conditions that tend to favor and those that inhibit and frustrate policy-development. More needs to be known about the significance for policy-formulation of such factors as technological change, the impact of crisis and catastrophe, industrial structure, political leadership, the input of economic analysis, the public's perception of the need for policy change, and the capacities of private parties to obstruct change or to convert public policy to their own uses. Such studies may be helpful in accounting in more specific terms for the traditonal lag in policy-development behind technological and economic change. They may also be able to throw some light on the problem of making case-by-case adjudication more productive of policy-formulation and policy-declaration. Perhaps special attention might well be accorded those regulatory programs in which the regulators make decisions that create or destroy enormous financial equities of private parties. We need to know whether any governmental agency can 
function effectively over time in an atmopshere of unbridled warfare among competing applicants for a single available operating permit worth millions of dollars. We also need to know whether the infusion of some elements of competition into a regulated industry tends to make the regulatory program not only more manageable by the agency, but more effective in reaching stated goals of public policy. We would find it helpful to know whether continuing judicialization of regulatory operations has, in turn, stimulated a search by both businessmen and agency personnel to find less time-consuming ways of reaching decisions.

In turning from analytical studies of processes of policy-formulation in specific regulatory contexts to the evaluation of regulatory policies, extraordinary difficulties may well be encountered, but they ought to be faced. Three problems illustrate the analytical complexity of the task. First, the cause-and-effect relationship between agency activities and policies on the one hand and the condition of the regulated industry may be extremely difficult to establish in the light of available knowledge and data. Second, the goals of regulation are likely to be least articulated and accepted in those programs involving the highest measure of controversy and current public concern; standards of evaluation do not readily emerge from statutes, legislative histories, and administrative decisions. And third, many regulatory programs are not self-contained, but spill over into related areas of program and policy. For example, evaluation of the impact of Interstate Commerce Commission regulation on interstate truckers may not be feasible without considering the impact on trucking not only of the work of the Bureau of Motor Carriers, but also of other parts of the ICC and the programs administered in several other agencies, including boards, semiautonomous commissions, departmental agencies, and noncabinet agencies.

In the light of these complexities, the analyst may have to settle often for something less than a wholly objective and scientific evaluation of regulatory policies. Nevertheless, if the limitations are fully acknowledged, useful contributions may be made. For example, it may be possible to adduce persuasive evidence that the achievement of policy goals will be more closely approximated through the provision of incentives that stimulate compliance with regulatory standards.

The imaginative development of policy alternatives that face squarely up to current obstacles to effective performance can be seen perhaps most clearly in the field of television and broadcasting. The way forward in this field would seem to lie not in further exhortation of Federal Communications Commissioners to plan policies, be consistent in applying standards in disposing of multiple applications for single frequencies, or be bold in stating a guiding policy on the relevance of program performance of licensees in proceedings for the renewal of licenses. Rather it would appear to be more fruitful to attempt a new approach toward policy that might overcome difficulties inherent in present policies.

\section{The Political Context of Regulation}

While the legal profession has remained more or less steadfast to the judicial model in appraising and reforming regulation, the fraternity of political scientists 
and public administration experts has increasingly accepted the finding that regulation is a political process. "Politics" is now rightly viewed not only as unavoidable, but as essential to the formulation of policies that bear some rational relation to economic and technological conditions. As one scholarly study concludes: ${ }^{6}$

The mentality which disdains "politics" and strives for a neutral and technical perfection rejects the very solvents that would reduce the obstructions.

Remarkably little empirical work has been done to describe and analyze the political context of particular regulatory programs. To illustrate: the administrative branch of the literature has freely generalized that regulated interests have been adept in capturing control of the regulators. The generalization gains some credence partly by repetition and partly by collateral support from the general literature of American politics, but studies in depth of the impact of regulated interests upon the regulatory agency and program have rarely been published. An understanding of the political aspects of regulation must build on further studies of the political settings of particular regulatory programs.

\section{E. Methodology}

Another urgent need in the research agenda of administrative regulation is the development and application of techniques of comparative analysis. Ways must be found to highlight and explain similarities and differences among regulatory programs and policies. We need to have better explanations of the curious phenomenon of the lack of adverse criticism of many regulatory programs despite their substantial reliance on conventional administrative modes of operation rather than formal procedures of rule-making and adjudication. We need to account for the fact that some regulatory programs, like the biologics standards program of the National Institutes of Health, have produced little or no litigation or cases for administrative adjudication and operate largely on the basis of discussion, negotiation, and joint consideration with regulated firms of problems and issues. We should be able to explain why two closely related bureaus in a single department that jointly administer a regulatory program, like the Bureau of Land Management and the Geological Survey in the Department of the Interior, have developed radically different patterns and traditions in exercising their regulatory functions. It would be very helpful to understand the role in current regulatory programs of nonadversary techniques and their significance compared to that of formal rule-making and adjudication. We need to discover the relationships between various regulatory patterns and such factors as the achievement of policy goals, fairness and equity in protecting the rights and privileges of individuals and firms, and relative capacity for imaginative formulation of policies. We need to know through examination of several programs whether regulation is likely to be more effective when some substantial element of competition is encouraged or maintained, or when the equities flowing to private parties from a government permit, license, or grant are not abnormally high. Comparative

- Eari Latham, The Politics of Railroad Coordination 277 (1959). 
analysis of regulatory programs seems best calculated to throw some empirical light on the conditions that make for relative success and failure in administrative regulation.

\section{III}

\section{TyPES OF EMPIRICAL WORK}

The types of empirical work that might usefully be projected may be suggested by outlining some proposed hypotheses for further investigation. These hypotheses have been developed in a preliminary attempt at comparative analysis of seven federal regulatory programs. ${ }^{7}$

Hypothesis 1 . The operations of regulatory programs in independent commissions are analogous to, and may be usefully compared with, regulatory activities of departments and other agencies.

Available studies and reports of the programs administered by the independent regulatory commissions suggests strongly that variations among commissions in terms of policies, political contexts of regulation, and sensitivity of political issues are probably more significant than their structural similarities. A comparison of the Securities and Exchange Commission and the Interstate Commerce Commission suggests that diversity among commissions runs very deep. The SEC's program on securities registration appears to have little relationship to other federal activities in the area of corporate and financial management. But the ICC's work in administering the agricultural-exemption provision of the Motor Carrier Act of $1935^{8}$ directly involes the in-

${ }^{7}$ This project on the regulatory process has been undertaken under the writer's direction; with the assistance of John Moore, Jack Brooks, and James Klonoski. The two-fold purpose of the study is (a) to discover the extent to which regulatory programs in operation involve processes and methods other than those relating to formal rule-making and formal adjudication; and (b) to formulate a conception of the regulatory process that embraces these operations. Seven regulatory programs in seven agencies are examined:

x. licensing of biologies (serums, vaccines, toxins, etc.), by the National Institutes of Health in the Department of Health, Education, and Welfare;

2. regulation incidental to the leasing of public lands for exploitation of oil and gas resources, in the Department of the Interior;

3. administration of the agricultural-exemption provision of the Motor Carrier Act, 49 Stat. 544 (1935), 49 U.S.C. $\$ 303$ (b) (1958), by the Interstate Commerce Commission;

4. administration of the registration and disclosure provisions of the Securities Act of $1933,4^{8}$ Stat. 78, 15 U.S.C. $\$ 77 f(1958)$, by the Securities and Exchange Commission;

5. administration of the Perishable Agricultural Commodities Act, 46 Stat. 53 I (1930), 7 U.S.C. $\$ \$ 499 a-499$ r ( 1958 ), by the Department of Agriculture;

6. regulation of federal savings and loan associations, by the Federal Home Loan Bank System; and 7. regulation of nuclear reactors, by the Atomic Energy Commission.

The study includes departmental agencies, independent commissions, and a government corporation. It includes programs relating to financial affairs, classic public-utility-type regulation; regulation for the protecting of public health and safery, regulation incidental to the management of the public domain, and industry-oriented regulation. It includes programs in which technology is uncertain and subject to profound and rapid change. Some of the programs, on the other hand, exhibit little of novelty in technology. Some programs affect only a few regulated firms, whereas others affect thousands of firms and individuals. Some are administered under tight central control in Washington, while others are highly decentralized to an extensive field staff. Some are substantially judicialized, while others rely extensively on normal administrative methods and processes.

${ }^{8} 49$ Stat. 544 (1935), 49 U.S.C. $\$ 303$ (b) (1958). 
terest of the Department of Agriculture. On the other hand, both programs involve a substantial ingredient of conventional administrative processes that often fall considerably short of formal rule-making and formal adjudication. Both programs operate in areas marked by certain changes in business techniques and technology, but the SEC processes several hundred cases annually, while the ICC deals with thousands. Politically speaking, the SEC program has been a highly stable one for at least a score of years, while the ICC program has embroiled the Commission in the politics of the farm bloc in Congress. At the same time, it may be useful to compare the biologics standards program of the National Institutes of Health with the SEC registration program. Both deal with relatively few firms. Both programs are set in motion at the beginning of an important business process-the sale of securities and the production of vaccines and toxins-not at some later stage of processing or distribution. In both instances, the protection of the public against abusive business practices is a powerful motive in the administration of regulations. One apparent consequence is a close identity of interest between the agency and its immediate regulatory clientele that has probably led to a clearer and sharper conception of the goal of public policy. Here it would seem to be most fruitful to make a detailed comparison of the NIH and SEC programs. The similarities are apt to be far more significant than differences in organizational structure.

Hypothesis 2. Much of the regulatory process works itself out not in terms of formal adversary-type proceedings, but rather in other types of administrative action.

In the comparative study of seven regulatory programs noted above, all involved some degree of use of nonadversary-type proceedings, although the variation from one program to another is striking. Even within agencies, differences can be noted in the practices of different bureaus or programs, and within a single program, important differences appear over time. In the case of the nuclear-reactor-licensing program in the Atomic Energy Commission, the unsettled state of reactor technology appears to be an influential factor in maximizing the need for close consultation between agency personnel and the reactor companies. When speed in reaching a decision is a paramount consideration, as it is in the administration of the Perishable Agricultural Commodities Act, there is resort to formal adversary proceedings only after attempts at administrative adjustment have clearly failed.

The use of techniques of surveillance and inspection also vary considerably and are generally highly symptomatic of the character of a regulatory program. The absence of a systematic program to review compliance with consent orders and decrees in the Antitrust Division and the Federal Trade Commission is primary evidence of the lack of interest in the agencies in appraising regulatory results and in keeping regulations and methods up-to-date. The less formal and more decentralized administrative pattern of the Geological Survey in handling its share of the minerals-leasing program contrasts sharply with the more formal, centralized, legalistic program of the Bureau of Land Management in the same area. The experience of the Federal Home Loan Bank System suggests that when the agency exercises 
a strategic control over its regulated clientele, such as power to take control of a business from private managers, pressures are created that compel utilization of a variety of administrative methods. This experience suggests that if the Federal Communications Commission actually used its license-renewal procedure as a device for enforcing broadcast standards, it would have to rely much more heavily upon such methods.

Hypothesis 3. Technical aspects of regulatory programs are among the most significant factors that must be embraced in any meaningful concept of the regulatory process.

The style, tone, and pace of a regulatory program seem to be affected strongly by technical considerations. Perhaps the most dramatic case is that of the Atomic Energy Commission's licensing programs. So long as reactor technology remains highly unstable and the requirements of safety uncertain, it will be difficult to keep promotional and regulatory objectives apart in actual operations in the AEC. Similarly, until profitable operation of nuclear reactors becomes feasible, AEC regulators cannot ignore financial considerations in their licensing work. These technical aspects of atomic regulation for safety purposes are major factors in the total setting of the regulatory program.

Similarly, several technical aspects of the marketing of fresh fruits and vegetables must be mastered in order to understand the basic character of regulation of these perishable commodities by the Department of Agriculture. Such a factor as the rapidity of deterioration of particular fruits or vegetables under variable conditions of climate, refrigeration, ripeness, etc., becomes crucial in day-to-day decision-making in the program. Knowledge of marketing and distribution patterns is an essential prerequisite to effective adjustment of differences between shippers and receivers. Hypothesis 4. Often regulation cannot be sharply separated from promotional programs.

As already indicated, it may be several years before the promotional and regulatory aspects of atomic energy programs can be substantially separated. Some programs, like the regulation of federal savings and loan associations, are administered by agencies with important promotional responsibilities. The Federal Home Loan Bank System both encourages the growth of federal savings and loan associations through a deposit insurance scheme and regulates them as a function of the insurance system. The National Institutes of Health are basically an organization devoted to the promotion of public health through scientific research, but the findings of its research scientists are basic to the exercise of its regulatory functions affecting vaccines and toxins. In fact, its regulatory staff is primarily a laboratory research staff who handle regulatory matters only as an aspect of their total job of scientific research. The registration of new issues of stock, as approved by the Securities and Exchange Commission, tends to promote public confidence in investment in corporate enterprises. 
Hypothesis 5. The effectiveness of a regulatory program is influenced by the level of production and distribution at which it is principally aimed.

In the Department of Health, Education, and Welfare, two bureaus administer somewhat similar programs designed to protect the health and safety of the consuming public: the Food and Drug Administration, and the National Institutes of Health. In regulating the distribution of vaccines, drugs, and other medications, the National Institutes of Health tend to be more effective than the Food and Drug Administration, in part because basic controls are aimed at the primary level of production of vaccines and toxins rather than some subsequent level in the process of distribution. Such regulation involves a relatively small number of pharmaceutical houses with whom the National Institutes are in close touch. The Food and Drug Administration aims its controls, under statutory direction, to the distribution, not the production, of products subject to its regulations. It is dealing, consequently, with thousands of firms and individuals of great variety, including some that are not readily identifiable or visible to the regulators and some that are unaccustomed to regulation. In the Food and Drug Administration, the task of compliance and enforcement is far more difficult. In the NIH, controls are more certain of application; they are more directly applied; they are more likely to be understood and complied with.

Hypothesis 6. Regulation is likely to be more effective when several of the following conditions are present:

a. coercion is minimized;

b. some incentives are provided to encourage compliance and to win consent;

c. the policy context of regulation is broad and flexible;

d. political leadership in behalf of regulation has been mobilized;

e. some element of competition in the regulated industry or trade is encouraged or maintained;

f. the equities accruing to private parties through a license, permit, or grant are not excessively high; and

g. the goals of regulation, as set forth in statutes, have acquired an accepted meaning and do not remain substantially unresolved or inchoate.

The testing of this comprehensive hypothesis through empirical work is designed to clarify the conditions under which a regulatory program is most likely to flourish and, conversely, the conditions that make for frustration and failure.

Hypothesis 7. Continuing judicialization of administrative regulation under the Administrative Procedure Act has encouraged the growth of nonadversary methods to dispose of regulatory business and may have stimulated wider recourse to ex parte contacts and communications.

This hypothesis illustrates the importance of pursuing empirical studies in areas of conventional interest to lawyers. For even in these areas, there has been a dearth of empirical observation and reporting. Despite the outpouring of legal materials, the roles of hearing examiners, appellate judges, and agency heads have not been 
examined adequately. The prospects of making case-by-case decisions more productive of policy have not been explored in the literature. The use of regulatory agencies as training-ground for the private practice of law has not been studied.

\section{ConcLusion}

The conception of the regulatory process that has dominated the literature has been founded on categories of analysis that have not been supported by empirical evidence. More empirical work is urgently needed to formulate new categories of analysis, establish appropriate levels of generalization, probe issues of public policy, and develop adequate methodologies for the analysis of regulatory processes. The hypotheses suggested for testing indicate roughly the types of empirical work that political scientists, lawyers, and economists must engage in in order to develop a meaningful operating concept of the regulatory process and focus attention on substantive issues of policy. 